\title{
Effects of the Propeller Advance Ratio on Delta Wing UAV Leading Edge Vortex
}

\author{
K. A. Kasim ${ }^{1 *}$, P. Segard ${ }^{2}$, S. Mat ${ }^{1}$, S. Mansor ${ }^{1}$, M. N. Dahalan ${ }^{1}$, N. A. R. N. Mohd \\ and M. N. M. Nasir ${ }^{1}$ \\ ${ }^{1}$ School of Mechanical Engineering, Faculty of Engineering, \\ Universiti Teknologi Malaysia, 81310 Johor Bahru, Johor, Malaysia. \\ ${ }^{2}$ EPF Graduate School of Engineering, 3 bis Rue Lakanal, 92330 Sceaux, France \\ Email: kamri7@live.utm.my
}

\begin{abstract}
Delta wing is a triangular-shaped platform that can be applied into the unmanned aerial vehicle (UAV) or drone applications. However, the flow above the delta wing is governed by complex leading-edge vortex structures which result in complicated aerodynamics behaviour. At higher angles of attack, the vortex burst can take place when the swirling flow is unable to sustain the adverse pressure gradient. More studies are needed to understand these vortex phenomena. This paper addresses an experimental study of active flow control called propeller on a generic $55^{\circ}$ swept angle sharp-edged delta wing model. In this experiment, a propeller was placed at two different locations. The first location was at the apex of the wing while the second position was at the rear of the wing. The experiments were conducted in a $1.5 \times 2.0 \mathrm{~m}^{2}$ closed-loop wind tunnel facility at Universiti Teknologi Malaysia. The freestream velocities were set at $20 \mathrm{~m} / \mathrm{s}$ and $25 \mathrm{~m} / \mathrm{s}$. The research consisted of an intensive surface pressure measurement above the wing surface to investigate the effects of rotating propeller towards the leading-edge vortex. The experiments were divided into four configurations. The clean wing configuration was performed without the propeller and followed by pusher-propeller configuration using 10-inch 9-inch propellers. The final configuration was the tractor-propeller with a 10-inch propeller. The results emphasise the influences of the propeller size and its location corresponding to vortex properties above the delta-winged UAV model. The findings had indicated that the vortex peak is increased when the propeller is installed for both pusher and tractor configurations. The results also indicate that the pressure coefficient is increased when the propeller advance ratio increases.
\end{abstract}

Keywords: Delta wing UAV; propeller; surface pressure; vortex; wind tunnel experiment.

\section{INTRODUCTION}

Unmanned Aerial Vehicle (UAV) is an aerial vehicle that operates without a pilot on board. UAVs can overcome the limitations of piloted aircraft such as unnecessary risk exposure towards pilots and aircrews during rescue missions or surveillance operations [1]. UAVs can be classified into fixed-wing, rotary-wing, ornithopter and entomopter based on their flying principal [2]. Delta wing is categorised as fixed-wing UAVs. Currently, delta wing has been implemented into UAVs application [1-4]. This includes both low speed and high-speed applications. The advantage of the delta wing compared to the conventional wing is it can produce power more efficiently and lowering the ratio of wetted area to volume [3, 4]. UAV commonly uses delta wing configuration with a swept angle of less than $55^{\circ}$. Thus, research on non-slender delta wing configurations has started to become more prominent [5]. There 
are several types of delta wing configurations being used in UAV such as tailless delta, cropped delta and cranked delta [6] as depicted in Figure 1.

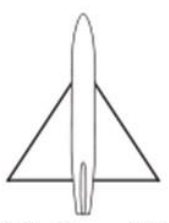

(a) Tailless delta

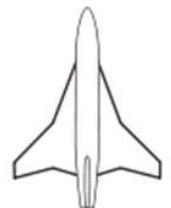

(e) Cranked arrow

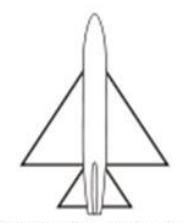

(b) Tailed Delta

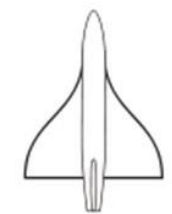

(f) Ogival delta

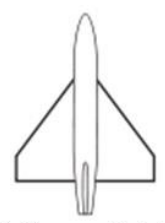

(c) Cropped delta

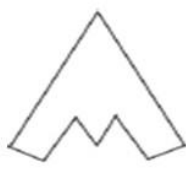

(e) Lambda

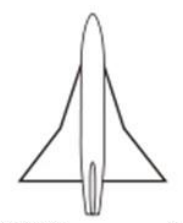

(d) Compound delta

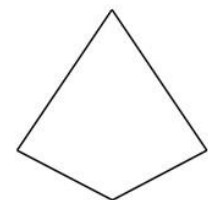

(f) Diamond

Figure 1. Types of delta wing [6].

The delta-wing planform generates more lift at a higher angle of attack than the conventional design [7]. Strong vortices generated at a high angle of attack produce highspeed flow above the wing, resulting in a lower pressure section on the wing [8]. Thus, the wing lift increases in a non-linear manner. Figure 2 illustrates the vortex structure and nonlinear vortex lift of the delta wing. Furthermore, strong leading-edge vortices on the wing enable the flow to remain attached on the surface even at a higher angle of attack [9]. This enables delta-winged aircraft to operate at high incidence compared to the conventional wing. However, at a high angle of attack, delta wing experiences vortex breakdown indicating the limitation of this planform. As the vortex breakdown develops on the wing, the vortex lift is diminished in the region behind the breakdown [7-9]. This affected the aerodynamic forces and moments of the wing especially lift and pitching moment [10].
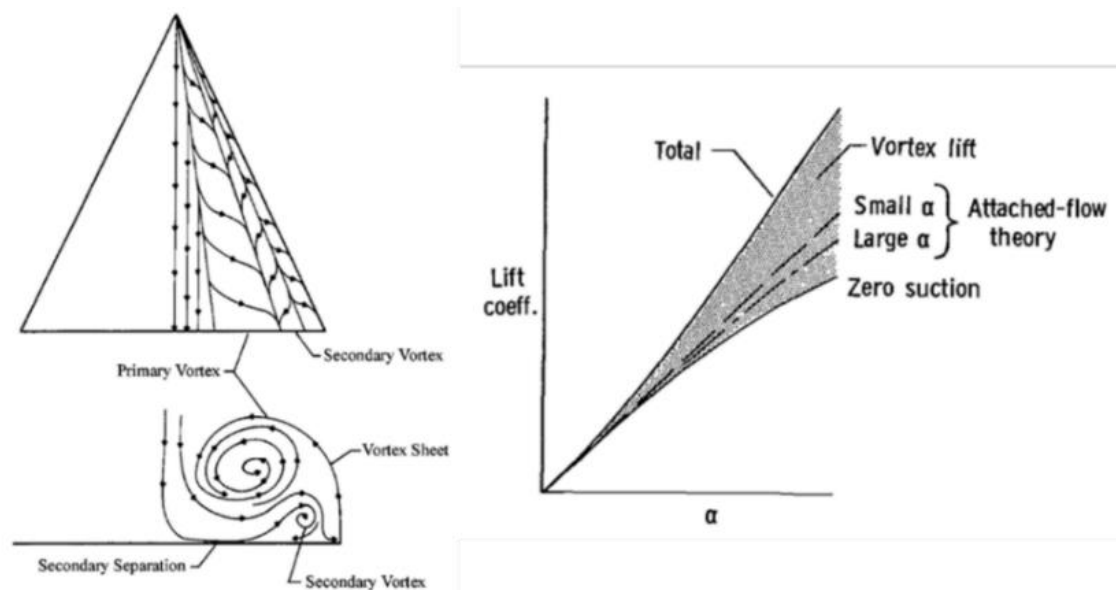

Figure 2. Structure of leading-edge vortex and vortex lift of delta wing [7, 8]

(Reprinted from Progress in Aerospace Sciences, 39, Nelson RC, Pelletier A, The unsteady aerodynamics of slender wings and aircraft undergoing large amplitude maneuvers, 185-248, Copyright (2003), with permission from Elsevier) 
The UAV industry is growing rapidly, including the delta-planform UAVs. Therefore, many studies have been conducted to study the effects of flow control on the delta wing [11]. Flow control techniques (active and passive) had been implemented on the delta wing to improve the vortex properties and delay the vortex breakdown [12]. One of the techniques is by using the rotating propeller, which can be categorised into downstream suction (pusher propeller), and upstream blowing (front propeller). For the smaller scale of $\mathrm{UAV} / \mathrm{MAV}$, the propeller is used as the propulsion system instead of the propulsive nozzle. Normally, delta wing UAV is equipped either with pusher or tractor propeller configurations. Figure 3 shows the two types of propeller configuration on the delta wing UAV. Studies have shown that the stall angle of the UAV and flow above the wing is improved if the propeller is installed on the wing [13-17].

In 2016, Kasim et al. performed an experiment on a sharp-edged delta wing model. The flow control used was the propeller. The propeller was placed at 3 different locations. They found that the installation of the propeller had improved the vortex strength because the accelerated flow from the propeller had created a lower pressure region on the wing [18]. This current project is carried out with a similar model but with a bigger diameter propeller. Thus, the purpose of this project is to determine the effects of propeller locations namely, tractor and pusher configurations on the leading-edge vortex above the non-slender deltawinged UAV with sharp leading-edge. The present study also explores the influence of the propeller advance ratio on the vortex properties above the wing.

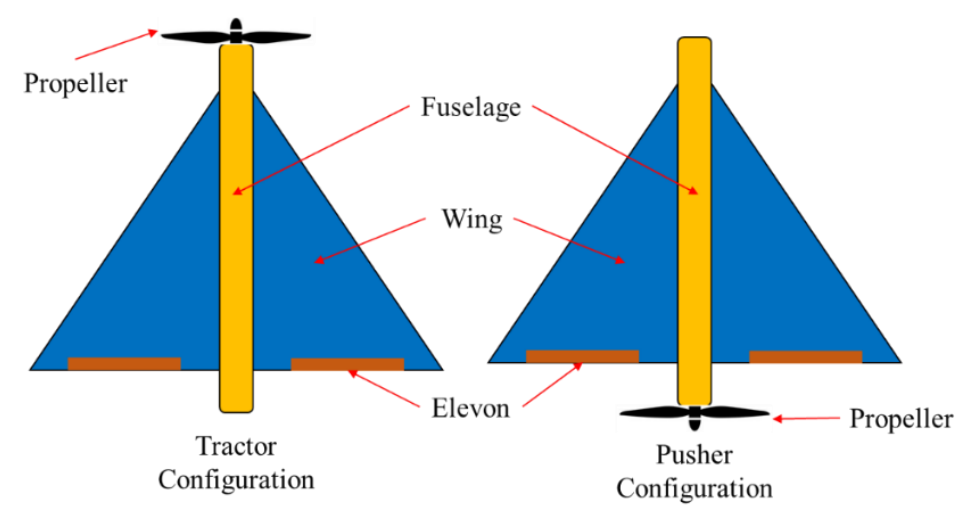

Figure 3. Propeller configuration for delta wing UAV.

\section{EXPERIMENTAL SETUP}

The UAV model was designed and fabricated locally in UTM Aerolab. The UAV model was designed based on a tailless delta type and has a $55^{\circ}$ sweep angle. Since the main objective of this project was to determine the propeller effects on the leading-edge vortex, the model had been designed with the sharp-edged and tailless platform. A tailless platform delta wing was chosen to prevent the formation of multiple vortices over the wing [19]. The inner portion of the wing also was a flat plate in order to prevent the flow from becoming more complicated. Several other factors such as the complexity of the model during the manufacturing had been taken into account during the design process. The planform of the model is shown in Figure 4. The fuselage was specially designed to be installed with the propeller at several locations. The mean aerodynamic chord (MAC) of the model is 493.7 $\mathrm{mm}$ and the span of the wing is $1062 \mathrm{~mm}$. The model had a thickness of $20 \mathrm{~mm}$. The UAV 
wind tunnel model was designed based on the delta-winged UAVs available on the market [18].

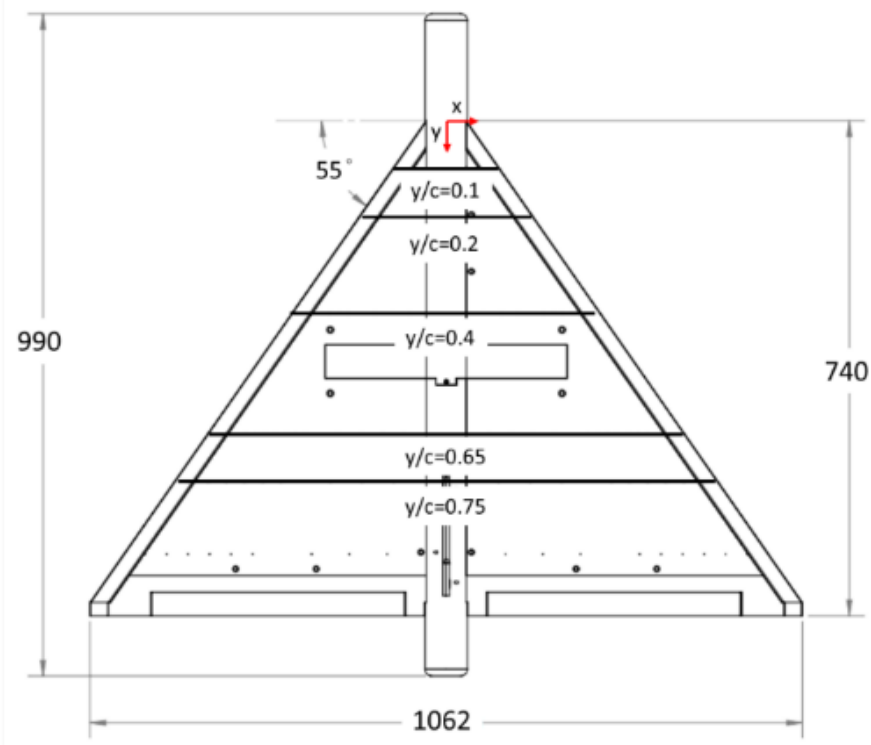

Figure 4. Model planform view with pressure measurements location.

The experiments were performed in a closed-loop wind tunnel UTM-LST with a test section of $1.5 \mathrm{~m} \times 2.0 \mathrm{~m} \times 6 \mathrm{~m}$. The tests were performed at freestream velocities of $20 \mathrm{~m} / \mathrm{s}$ and $25 \mathrm{~m} / \mathrm{s}$ corresponding to Reynolds numbers of $0.6 \times 10^{6}$ and $0.8 \times 10^{6}$. The Reynolds number is based on the mean aerodynamic chord. For the electric motor system, a brushless outrunner motor was used to spin the propeller. In this project, the speed of the propeller was set at $4800 \mathrm{rpm}$ for all tests. The experiments were divided into four configurations, i.e., clean wing configuration experiment without propeller and followed by a pusher-propeller experiment using 10-inch and 9-inch propellers. The final experiment was with a 10-inch propeller for tractor-propeller configuration. Figure 5 shows the installation of the wind tunnel model in the closed test section. Intensive surface pressure measurements were employed during the experiments. The pressure on the top surface of the model was measured by a pressure tap with a diameter of $1 \mathrm{~mm}$. The pressure tap was connected to the electronic pressure scanner through a vinyl tube. The experiments were conducted at angles of attack ranging from $0^{\circ}$ to $18^{\circ}$. Table 1 shows the experimental conditions for this project.
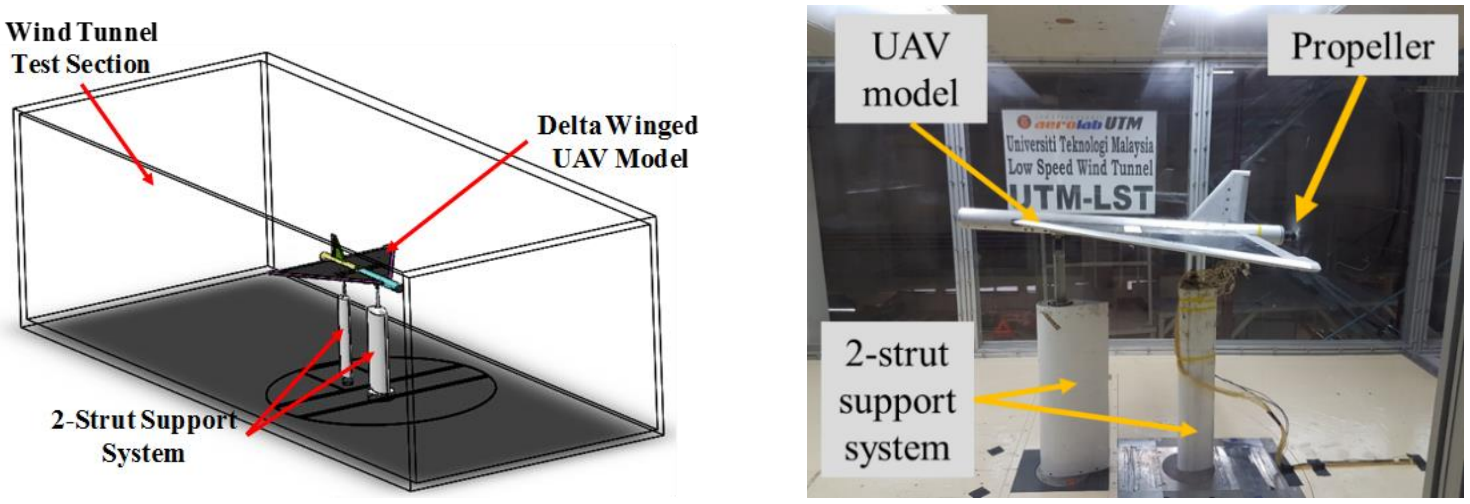

Figure 5. Wind tunnel model installation inside a closed test section. 
Table 1. Experimental conditions.

\begin{tabular}{lc}
\hline Parameters & Value \\
\hline Plane of measurement $\left(\mathrm{y} / \mathrm{c}_{\mathrm{r}}\right)$ & $0.1,0.2,0.4,0.65,0.75$ \\
Freestream velocity $(\mathrm{m} / \mathrm{s})$ & 20,25 \\
Reynolds number & $0.6 \times 10^{6}, 0.8 \times 10^{6}$ \\
Angle of attack, $\alpha\left(^{\circ}\right)$ & $0-18($ step: 3$)$ \\
Propeller size $($ inch) & 9 (pusher \& tractor), 10 (pusher) \\
Propeller rotational speed (rpm) & 4800 \\
Propeller advance ratio $(\mathrm{J})$ & $0.984,1.093,1.23,1.367$ \\
\hline
\end{tabular}

Propeller advance ratio $(\mathrm{J})$ is propeller rotational frequency compared to the free stream speed. The advance ratio becomes high when an aircraft is travelling at high speed and at a slower propeller rotation. Meanwhile, the low advance ratio means that the propeller rotation is higher compared to free stream speed. The advance ratio can be expressed in term of $\mathrm{J}=\mathrm{V} / \mathrm{nD}$, where $\mathrm{V}$ is freestream velocity, $\mathrm{n}$ is propeller rotating speed and $\mathrm{D}$ is propeller diameter.

\section{RESULTS}

This section discusses the findings from experimental surface pressure measurement carried out in this project. To differentiate the propeller effects on vortex performance, results from the propeller configurations were evaluated with the results from the clean wing.

\section{Clean Wing Configuration (No Propeller)}

Discussion of the results begins with the clean wing configuration. Figure 6 presents the results for clean wing configuration for both angles of attack and Reynolds number effects. At $\alpha=0^{\circ}$, no vortex had developed on the upper surface of the wing. As the angle of attack increased to $\alpha=3^{\circ}$, a suction peak was observed in the leading-edge region indicating the formation of a leading-edge vortex. The primary vortex developed at the apex of the wing due to the sharp leading-edge properties $[18,20]$. Figure $6(\mathrm{a})$ and $6(\mathrm{~b})$ show a clear increasing trend in primary vortex suction peak with increasing angle of attack. A closer examination at the trailing-edge region in Figure $6(\mathrm{~b})$ at $\mathrm{y} / \mathrm{c}_{\mathrm{r}}=0.65$ and 0.75 shows the vortex breakdown phenomena on the wing beyond $\alpha=15^{\circ}$. Earlier vortex breakdown was discovered for this wing configuration due to non-slender wing characteristics. The present finding also supported the previous study on non-slender delta wing [5, 7, 10, 21] which concluded that the vortex breakdown moved upstream as $\alpha$ increased. In Figure 6(c), it is noticeable that the suction peak of the primary vortex increases when the Reynolds number is increased. The results are in line with earlier literature $[18,22]$ that found only a small change in vortex suction peak when the Reynolds number was increased. However, the increase in the Reynolds number does not have any influence on the vortex breakdown in the trailing edge area at $\mathrm{y} / \mathrm{c}_{\mathrm{r}}=0.65$ and 0.75 .

Figure 7 shows the comparison between the current results with the experiments carried out by Kasim [18] at $y / c_{\mathrm{r}}=0.65$ and $\alpha=12^{\circ}$. The pressure distributions were compared at both Reynolds numbers of $0.6 \times 10^{6}$ and $0.8 \times 10^{6}$. From the figure, the data differs by about $0.1 \%$ to $3.8 \%$ only. 


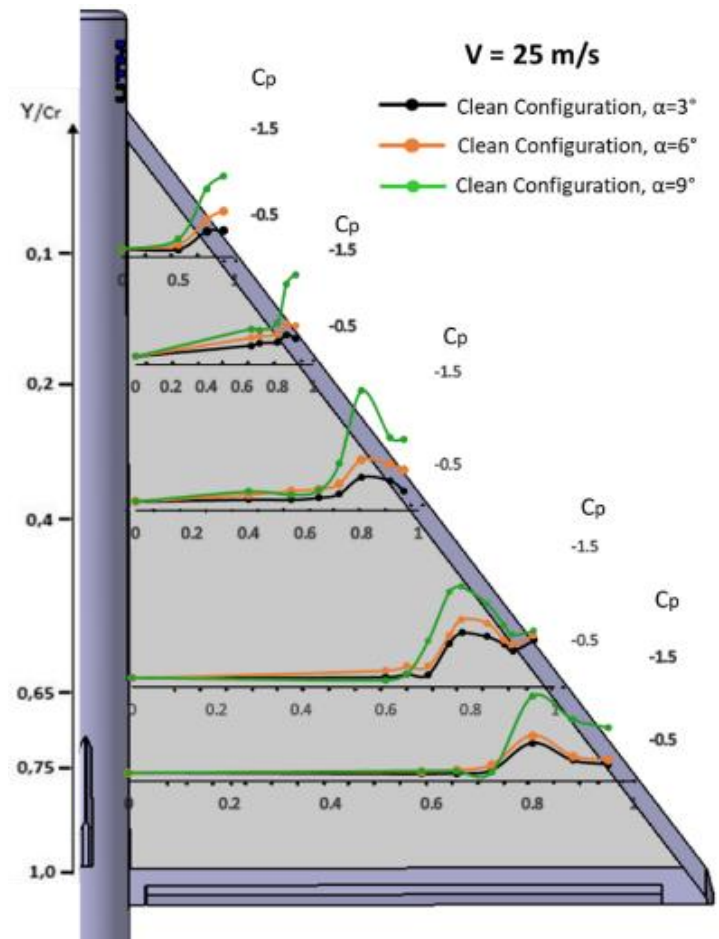

(a) $\alpha=3^{\circ}, 6^{\circ}, 9$

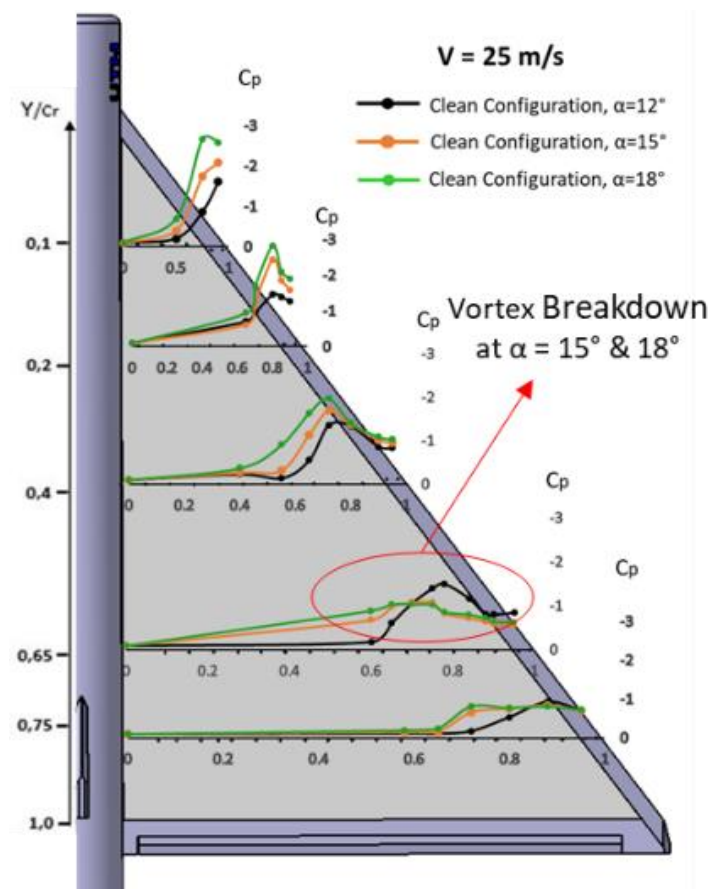

(b) $\alpha=12^{\circ}, 15^{\circ}, 18^{\circ}$ 


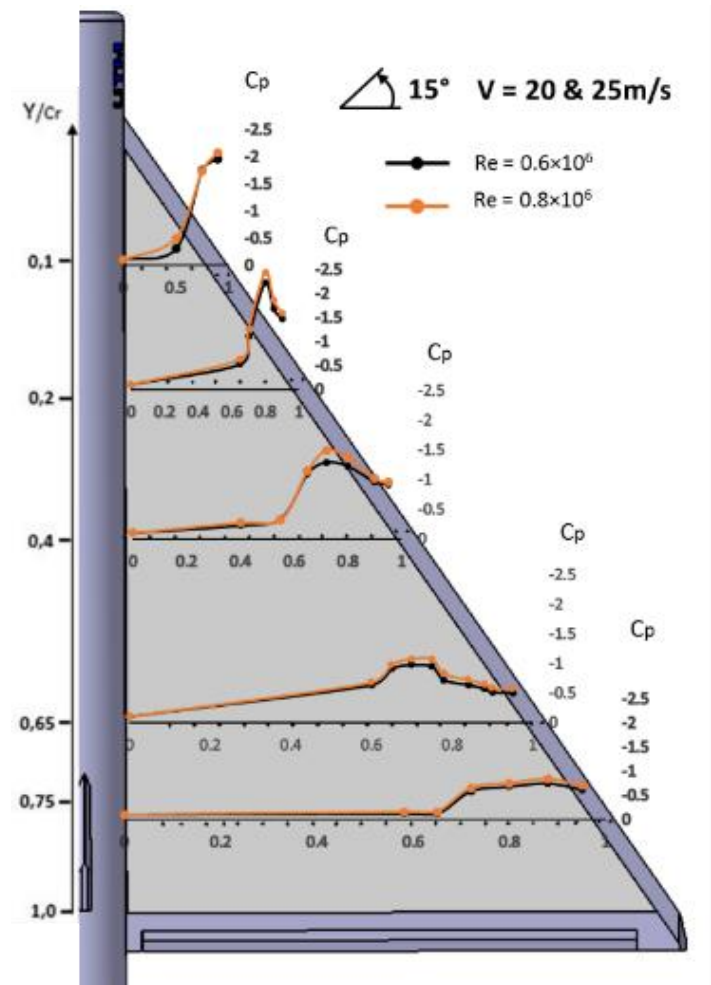

(c) $\operatorname{Re}=0.6 \times 10^{6}, 0.8 \times 10^{6}$

Figure 6. Effects of $\alpha$ and Re for clean configuration.
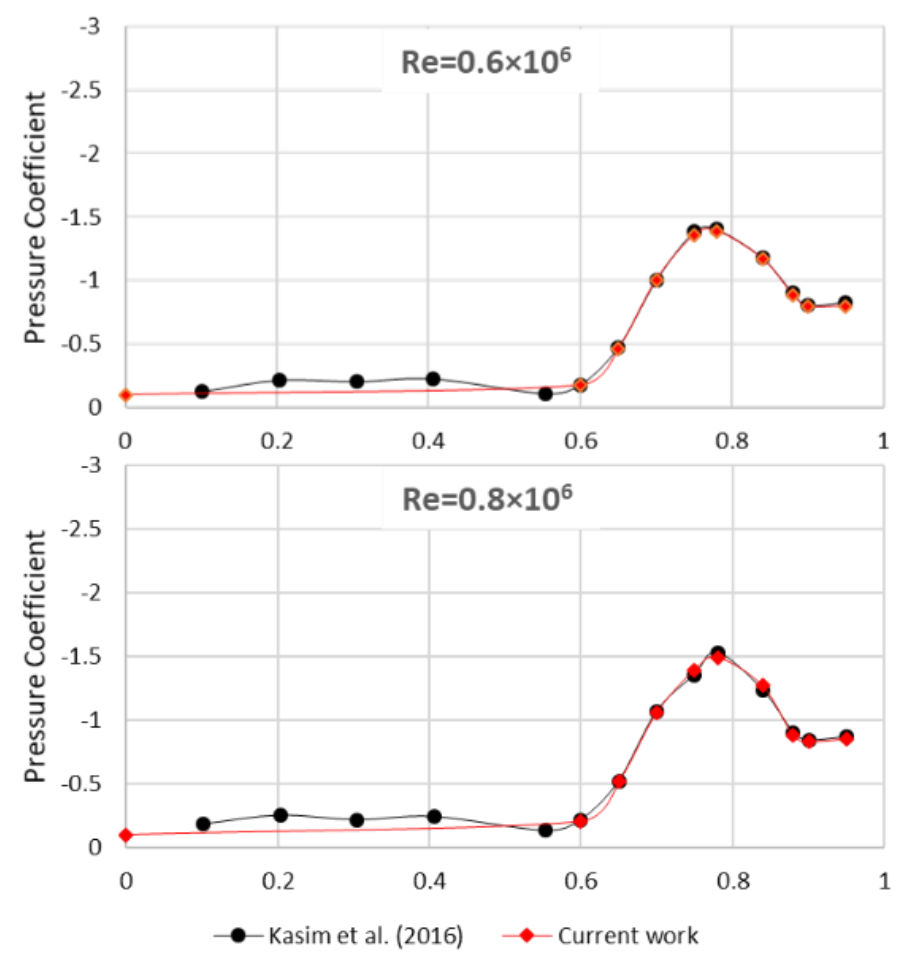

Figure 7. Comparison of clean wing configuration pressure distribution $\left(\mathrm{y} / \mathrm{c}_{\mathrm{r}}=0.65\right)$. 


\section{Propeller Configurations (Pusher \& Tractor)}

Figure 8 compares the influence of propeller configurations on the pressure coefficients above the wing at $\alpha=15^{\circ}$. For most cases, the propeller installation has increased the local pressure, $C_{P}$ on the wing surface which agrees relatively well with previous works $[18,22$, $23]$. The propeller flow has increased the pressure gradient in the suction area above the wing and therefore influencing the vortex strength. However, the positive effects from the propeller flow are diminished by the vortex breakdown for all test cases near the trailing edge of the wing. The additional flow from the propeller seems incapable to overcome the adverse pressure gradient generated by the trailing edge. This shows that the presence of the propeller is unable to delay the vortex breakdown downstream at $y / c_{r}=0.65$. In spite of that, the positive effects on the flow excitation in increasing the pressure coefficient can still be observed for propeller cases after the breakdown. When the airspeed is increased to $25 \mathrm{~m} / \mathrm{s}$, a nominal change in the vortex system is observed.

Figure 8(a) shows pressure distribution plots on the wing at $\mathrm{Re}=0.6 \times 10^{6}$ for all three configurations. The finding of the present study suggests that the pusher propeller has shown better improvements in the suction peak of the primary vortex over the tractor configuration. The results of this study show that the pusher propeller configuration has increased the maximum suction peaks by $14.76 \%$ to $23.79 \%$ at a freestream velocity of $20 \mathrm{~m} / \mathrm{s}$. Meanwhile, the tractor configuration has only increased the maximum suction peaks by $4.8 \%$ to $16.7 \%$. The result is in good agreement with past studies by [18], which found that installation of the propeller in the rear position of the model capable to improve the vortex suction peak better. The tractor configuration significantly increases the size of the primary vortex near the apex $\left(\mathrm{y} / \mathrm{c}_{\mathrm{r}}=0.1\right)$ by $16.79 \%$ suction peak improvement.

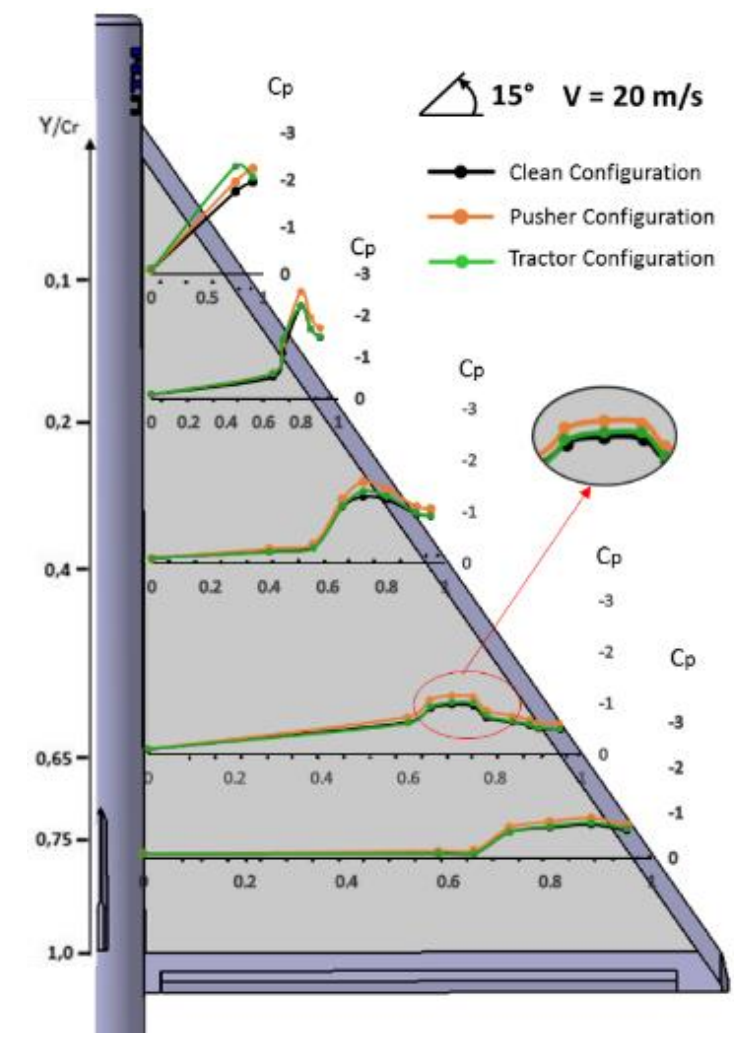

(a) $\mathrm{Re}=0.6 \times 10^{6}$ 


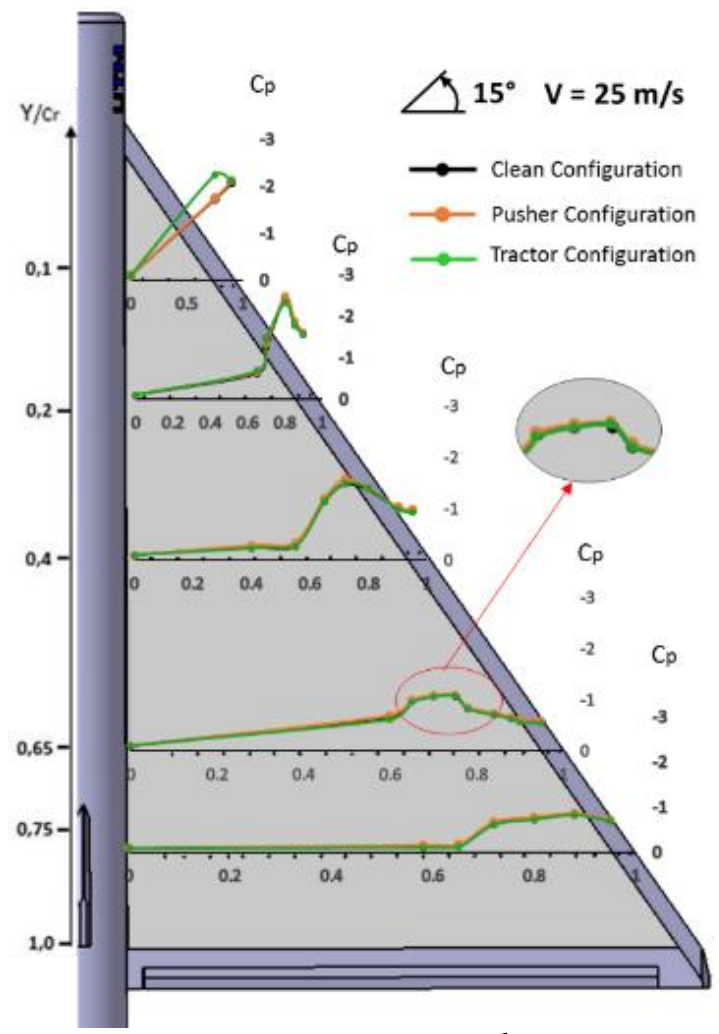

(b) $\operatorname{Re}=0.8 \times 10^{6}$

Figure 8. Propeller effects at different freestream velocity.

However, at downstream $y / c_{r}=0.1$, the suction peak from pusher propeller was higher. This suggesting that the flow from the propeller at the front may disrupt the vortex progression consistency toward trailing edge. More experiment needed to verify this hypothesis. Still, a slight increase of the suction peak by $4 \%$ to $9 \%$ was observed at $y / c_{r}=0.1$ for this configuration. Figure 8(b) presents the results above the wing for clean, pusher and tractor configurations when the Reynolds number increased to $0.8 \times 10^{6}$. A similar trend was observed here. The tractor configuration has increased the suction peak significantly at $\mathrm{y} / \mathrm{c}_{\mathrm{r}}=0.1$. A similar observation is also observed for pusher type. Further analysis showed that only a slight increase in pressure distribution above the wing for both propeller configurations. The average improvement on suction peaks for tractor and pusher configurations are $2.69 \%$ and $3.34 \%$ respectively. Further aft of the wing, there is no clear significant change in the flow topology as it does at $\mathrm{Re}=0.6 \times 10^{6}$.

\section{Propeller Advance Ratio, J}

The influence of the propeller advance ratio, $\mathbf{J}$ on the leading-edge vortex is depicted in Figure 9. A selected case of pusher propeller configuration was chosen to study the effects of propeller advance ratio towards pressure distributions above the wing. Figure 9(a) presents the pressure distribution above the wing for 9-inch propeller at $20 \mathrm{~m} / \mathrm{s} \mathrm{and} 25 \mathrm{~m} / \mathrm{s}$ that correspond to the advance ratio of $\mathrm{J}=1.093$ and $\mathrm{J}=1.367$, respectively. Figure $9(\mathrm{~b})$ depicts the pressure distribution at the lower advance ratio, $\mathrm{J}=0.984$ and $\mathrm{J}=1.23$. This is done by increasing the propeller diameter to $10 \mathrm{in}$. Both results indicated that the maximum suction peak is decreased when the freestream velocity increases. The main observation from the results here showed that the maximum suction peak is reduced by $6 \%$ to $11 \%$ when the 
freestream velocity is increased to $25 \mathrm{~m} / \mathrm{s}$. These results are likely to be linked to the unsteady flow from the propeller. More experiments are needed to verify this.

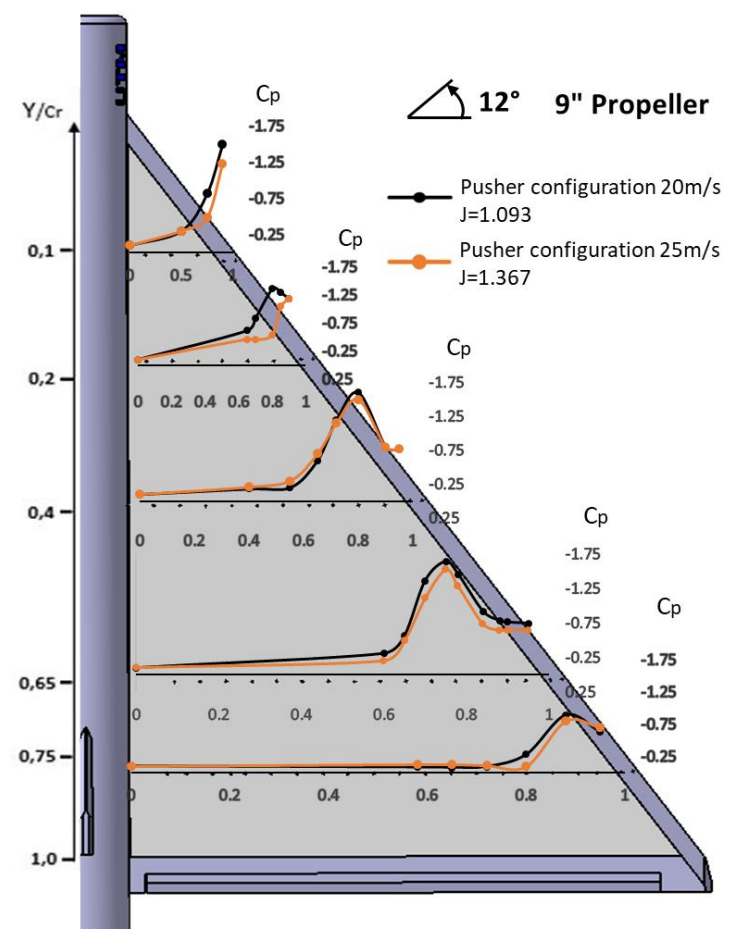

(a) 9-inch propeller

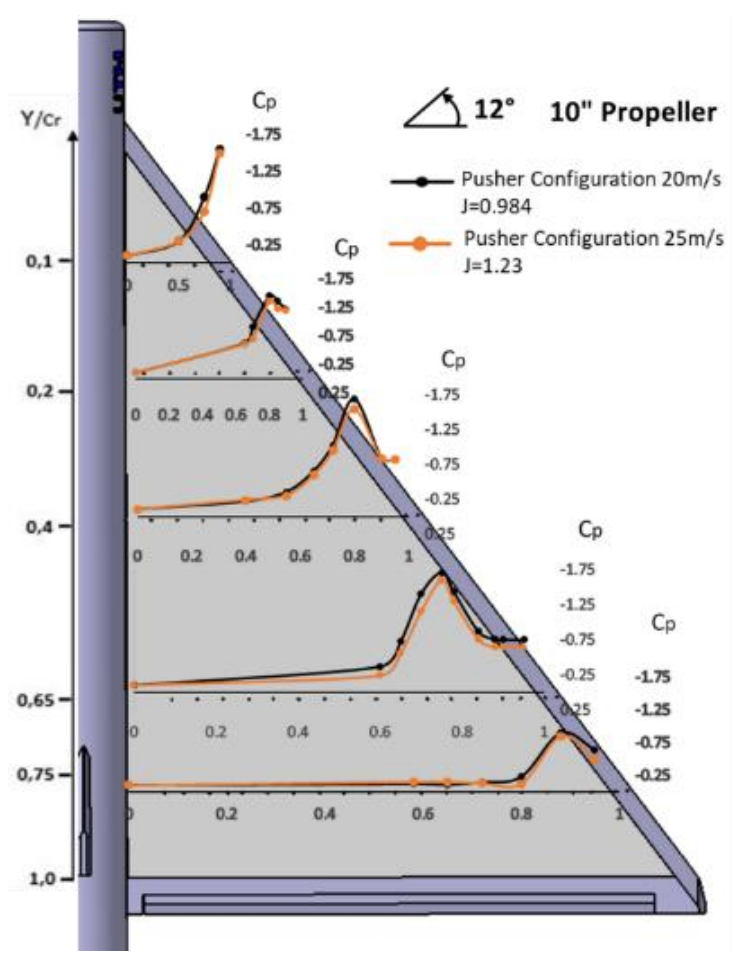

(b) 10-inch propeller

Figure 9. Advance ratio effects for pusher configuration. 
For the purpose of verifying the effects of propeller advance ratio on the vortex development above the wing, the surface pressure on the spanwise distribution is plotted at $\mathrm{y} / \mathrm{c}_{\mathrm{r}}=0.65$, this is shown in Figure 10. The pressure distribution for clean wing configuration is used to emphasise the effects of advance ratio. At the lowest value advance ratio $\mathrm{J}=0.984$, the maximum suction peak is increased by $22.83 \%$. From the figure, the maximum suction peak decreases when the advance ratio is increased. At the highest advance ratio of $\mathrm{J}=1.367$, the maximum suction peak increases by $9.93 \%$ only. The reduction in primary vortex suction peak is linked with the higher value of $\mathrm{J}$, which reflects the effect of freestream being more dominant than flow from the propeller. The present findings also support studies $[18,22$, 23 ], which concluded that the amplification of the vortex structure on the delta wing was observed to favour low advance ratios.

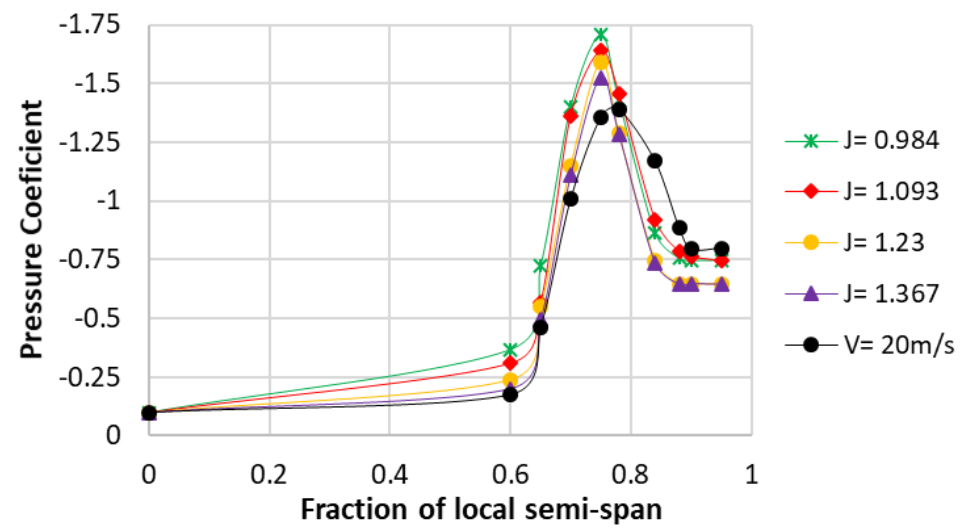

Figure 10. Advance ratio effects on the spanwise pressure distribution.

\section{CONCLUSION}

An experimental study on $55^{\circ}$ generic delta wing UAV model had been performed to determine the effects of propeller advance ratio on leading-edge vortex. The research showed the general flow characteristics of a non-slender delta wing with the sharp leading edge at different flow conditions, namely Reynolds number and angle of attack. It was found that the vortex breakdown developed on the wing at $\alpha=15^{\circ}$ onwards. The vortex breakdown moved upstream as the angle of attack increased. The results of this study indicate that the vortex development on delta wing is influenced by propeller actuation. The maximum suction peak had increased from $14.76 \%$ to $23.79 \%$ for pusher propeller configuration. When the propeller was placed in front of the model, the maximum pressure peak increased from $4.8 \%$ to $16.7 \%$ only. These findings show that the pusher propeller configuration is able to enhance vortex structure better than tractor configuration. Another significant finding from this study is that the propeller advance ratio has influenced the maximum suction peak of the primary vortex. The maximum suction peak is reduced by $6-11 \%$ when the advanced ratio is increased. The results also show that the maximum suction peak is increased by $22.83 \%$ when the advance ratio is at $\mathrm{J}=0.984$.

\section{ACKNOWLEDGEMENT}

This research was supported by grants from the Ministry of Higher Education of Malaysia and Universiti Teknologi Malaysia (FRGS Grant R.J130000.7824.4F718 \& 18H06). The author, Khushairi Amri Kasim gratefully acknowledges the scholarship from UTM Zamalah 
for his PhDs' study. The data presented, the statements made, and views expressed are solely the responsibility of the authors.

\section{REFERENCE}

[1] Teli SN, Jagtap M, Nadekar R, et al. Unmanned aerial vehicle for surveillance. International Journal of Scientific \& Technology Research 2014; 3: 256-260.

[2] Sudhakar S, Chandankumar A, Venkatakrishnan L. Influence of propeller slipstream on vortex flow field over a typical micro air vehicle. Aeronautical Journal 2017; 121 : 95-113.

[3] Tajima S, Akasaka T, Kumon M, et al. Guidance control of a small unmanned aerial vehicle with a delta wing. In: Australasian Conference on Robotics and Automation, ACRA. Sydney, 2013, pp. 2-4.

[4] Nakashima K, Okabe K, Ohsima Y, et al. Small unmanned aerial vehicle with variable geometry delta wing. In: 5th International Symposium on Advanced Control of Industrial Processes. Hiroshima, 2014, pp. 1-5.

[5] Tu H, Green MA. Forces and flow structure around swept wings. In: 2018 Fluid Dynamics Conference. Atlanta, 2018. Epub ahead of print 2018. DOI: 10.2514/6.2018-2913.

[6] Pevitt C, Alam F. Static computational fluid dynamics simulations around a specialised delta wing. Computers and Fluids 2014; 100: 155-164.

[7] Nelson RC, Pelletier A. The unsteady aerodynamics of slender wings and aircraft undergoing large amplitude maneuvers. Progress in Aerospace Sciences 2003; 39: 185-248.

[8] Polhamus EC. A concept of the vortex lift of sharp-edge delta wings based on a leading-edge-suction analogy. Washington D.C., 1966. Epub ahead of print 1966. DOI: 10.1088/0143-0807/36/6/065030.

[9] Brett J, Ooi A. Effect of sweep angle on the vortical flow over delta wings at an angle of attack of $10^{\circ}$. Journal of Engineering Science and Technology 2014; 9: 774-789.

[10] Gursul I, Gordnier R, Visbal M. Unsteady aerodynamics of nonslender delta wings. Progress in Aerospace Sciences 2005; 41: 515-557.

[11] Sharifi Ghazijahani M, Yavuz MM. Effect of thickness-to-chord ratio on aerodynamics of non-slender delta wing. Aerospace Science and Technology 2019; 88: 298-307.

[12] Gursul I, Wang Z, Vardaki E. Review of flow control mechanisms of leading-edge vortices. Progress in Aerospace Sciences 2007; 43: 246-270.

[13] Galiński C, Lawson NJ, Żbikowski R, et al. Delta Wing with Leading Edge Extension and Propeller Propulsion for Fixed Wing MAV. In: 24th International Congress of the Aeronautical Sciences. Yokohama: ICAS 2004, 2004, pp. 1-10.

[14] Galinski C, Mieloszyk J. Results of the Gust Resistant MAV Programme. In: 28th International Congress of the Aeronautical Sciences. Brisbane: ICAS 2012, 2012, pp. $1-10$.

[15] Mieloszyk J, Galiński C. Assessment of the concept of a propeller working in a slot in the middle of wing of a micro air vehicle. Archive of Mechanical Engineering 2013; 60: 269-282.

[16] Choi S, Ahn J. A Computational Study on the aerodynamic influence of a pusher propeller on a MAV. In: 40th Fluid Dynamics Conference and Exhibit. Chicago, 2010, pp. 1-8.

[17] Ahn J, Lee D. Aerodynamic Characteristics of a micro air vehicle and the influence 
of propeller location. In: 31st AIAAApplied Aerodynamics Conference. San Diego, 2013, pp. 1-9.

[18] Kasim KA, Mat S, Ishak IS, et al. Effects of propeller locations on the vortex system above delta-shaped UAV model. In: 30th Congress of the International Council of the Aeronautical Sciences, ICAS 2016. Daejeon: ICAS 2016, 2016, pp. 1-10.

[19] Zhang X, Wang Z, Gursul I. Control of multiple vortices over a double delta wing. In: 47th AIAA Fluid Dynamics Conference. Denver, 2017, pp. 1-27.

[20] Mat S Bin, Green R, Galbraith R, et al. The effect of edge profile on delta wing flow. Proceedings of the Institution of Mechanical Engineers, Part G: Journal of Aerospace Engineering 2016; 230: 1252-1262.

[21] Zharfa M, Ozturk I, Yavuz MM. Flow structure on nonslender delta wing: reynolds number dependence and flow control. AIAA Journal 2016; 54: 880-897.

[22] Zain NM, Mat S, Kasim KA, et al. Wind tunnel experiments on a generic sharp-edge delta wing UAV model. Journal of Advanced Research in Fluid Mechanics and Thermal Sciences 2017; 40: 18-26.

[23] Traub LW. Effect of a pusher propeller on a delta wing. Aerospace Science and Technology 2016; 48: 115-121. 